\title{
Expression of Insulin-like Growth Factor 1 (Igfl) and its Receptor (Igfrl) in Two Extremely Pre-Term Placentas
}

\author{
Ilze Kreicberga*, Mara Pilmane**, Dace Rezeberga* \\ *Department of Obstetrics and Gynecology, Riga, Latvia \\ **Institute of Anatomy and Anthropology, Riga Stradins University, Riga, Latvia
}

\begin{abstract}
Summary
Today extremely premature children readily survive; good quality of life can be reached only with research and technology based approaches, therefore understanding of molecular processes taking place in pre-term placentas can be of practical value both for neonatology and pediatric surgery, as complications of prematurity quite often require surgical interventions. The present case report describes the expression of one of the most significant growth factors IGF1 and its receptor IGFR1 in placentas after extremely pre-term deliveries of 22 and 23 gestational weeks and their correlations with clinical findings of corresponding extremely premature children. Significantly more beneficial clinical course is represented by a child with clinically less advantageous situation: smaller gestational age (22w versus $23 \mathrm{w}$ ) and birthweight (540g v. $650 \mathrm{~g})$, born in the first vaginal delivery (v. repeated delivery) and recently ruptured membranes (v. PPROM > 72 hours). Placental cells of this child contained abundance of IGF1 and IGFR1 positive structures ( $v$. few structures in the other one), possibly revealing better protective features of placenta, improving survival capabilities of the neonate in cases of extreme prematurity.
\end{abstract}

\section{AIM OF THE DEMONSTRATION}

The survival and good quality of life of extremely prematurily born children is one of the most challenging tasks of neonatology; its fulfillment requires research based approaches. Takizawa et al. (1) in 2007 suggested immunohistochemistry (IHC) to be useful for the clinical praxis. We evaluated the expression of 11 markers in the post-delivery placentas of different gestational ages, including the most potent growth factor, described by Peters et al. in 2012 (2) as a diagnostic marker of growth hormone deficiency, IGFl and its receptor IGFRl. IGFl and IGFR l have been found in the placentas of various gestational ages; Kumar et al. (3) in 2012 found downregulation of IGFl with an advancing gestational age, alerting its possible role in extreme prematurity. We also found negative correlations of the expressions of IGFI and IGFR I with the gestation; just one of the extremely pre-term post-delivery placentas showed unusually weak immunoreactivity, correlating with the clinical findings. Clinically interesting was comparison with another case with a strong immunoreactivity of IGFI and IGFR I. The other researched molecular markers in those two placentas were not so different.

\section{CASE REPORT}

In 2011, an IHC examination of 53 placentas of various gestational ages, acquired in the Riga Maternity hospital, was performed at the Latvian Institute of Anatomy and Anthropology. The study was approved by the Ethics comittee of the Riga Stradins university. Samples from identical central and peripheral places of placentas were taken immediately after delivery and placed into preservative; processed by antibodies IGFl (mouse monoclonal, 1: 50, R\&D) and IGFR 1 (goat polyclonal, 1: $100, R \delta D)$; assessed visually by the same researcher at the same day; amount of cells, containing markers, were evaluated in the range from 0 (none) to ++++ (abundace) (4). IGFI and IGFR I mainly were contained by the cells of cytotrophoblast and extravillous trophoblast.

Two placentas: $22 \mathrm{w}$ and $23 \mathrm{w}$ revealed significantly different expressions of IGFl and IGFR I (Figure 1).

Case A: mother 20 years of age, normal $22 \mathrm{w}$ pregnancy, first vaginal delivery, a girl of 540g. No antenatal corticosteroids. The girl presented $2^{\text {nd }}$ grade intraventricular hemorrhage (IVH) and moderate respiratory distress syndrome (RDS). Unusually benign clinical course for the gestational age.

Case B: mother 36 years of age, normal 23w pregnancy, PPROM $>72$ hours, third vaginal delivery of a boy of $650 \mathrm{~g}$. No antenatal corticosteroids. The boy presented 3rd grade IVH and severe RDS, died on the third day of life due to extreme prematurity. 


\section{DISCUSSION}

Clinically cases A and B were somehow similar: mothers had similar social statuses, body composition (body mass index 24 and 21), no high risks of infections or pre-term deliveries. Both pre-term delieveries were vaginal in the gestation of 22 and 23 weeks, without antenatal prophylaxis of dexamethasone, birthweight of children 540 and 650 grams.

Other studies have shown correlations of IGF1/IGFR I in the placental tissues with the weight of the neonate: Iniguez et al. (5) found higher expression of IGFl and IGFR I in the placentas of small for gestational age (SGA) infants. In our case both of the children were appropriate for their gestational age; placenta A had much stronger expression of IGFl and IGFR l (abundant $++++)$ and a child with a lower Ponderal index (PI) of 2.0; placenta B had much weaker (occasional $0 /+$ ) expression of IGFl and IGFRl and a child with a higher PI (2.96). In this gestational age leanness (lower PI) could be underataken as disadvantage, in our case it was the beneficial case.

Preterm premature rupture of membranes (PPROM) have been described in 2012 by Blumenfeld et al. (6) as decreasing mortality among children of 24 to 26 weeks of gestation; in our case child A without PPROM showed better survival. Loukovaara et al. (7) in 2002 found no differences of the expression of IGFl in the cases of PROM; probably PPROM had no impact on the expression of IGF1 in our case. Our findings could be more correlative with studies described by Isgaard et al. (8) in 2007 on the capability of IGF1 to protect and regenerate human brain.

We concluded that the expression of IGFl and IGFR I in the placental cells probably indicate the survival capabilities of pre-mature newborns; further studies could suggest application of IGF1 in the management of extremely low birth weight infants.

Conflict of interest: None

\section{REFERENCES}

1. Takizawa T, Eguchi H, Namimatsu Sh, Jeschke U, Fuchs R, Robinson JM. Histochemistry for Placenta Research: Theory and Application // J Nippon Med Sch, 2007; 74(4):268-273.

2. Peters CJ, Dattani MT. How to use insulin-like growth factor 1 (IGF1) // Arch Dis Child Educ Pract Ed, 2012; 97(3):114-8. Epub 2012 Jan 20.

3. Kumar N, Leverence J, Bick D, Sampath V. Ontogeny of growth-regulating genes in the placenta // Placenta, 2012;33(2):94-9.

4. Pilmane M, Rumba I, Sundler F, Luts A. Patterns of distribution and occurrence of neuroendocrine elements in lungs of humans with chronic lung diseases // Proceedings of the Latvian Academy of Sciences, 1998; B, 52, 144-152.

5. Iniguez G, Gonzalez CA, Arganona F, Kakarieka E, Johnson MC, Cassorla F. Expression and protein content of IGF-I and IGF-I receptor in placentas from small, adequate and large for gestational age newborns // Horm Res Pediatr, 2010; 73(5):320-7.

6. Bumenfeld YL, LeeHC, Gould JB, LangenES, Jafari A, El-Saved YY. The effect of preterm premature rupture of membranes on neonatal mortality rates // Obstet Gynecol, 2010 Dec;116(6):1381-6.

7. Loukovaara $\mathrm{M}$, Koistinen $\mathrm{R}$, Kalme $\mathrm{T}$, Kurki $\mathrm{T}$, Leinonen $\mathrm{P}<$ Sepp l M.Serum insulin-like growth factor-I and insulin-like growth factor binding protein-3 in premature rupture of membranes // Acta Obstet Gynecol Scand, 2002 Oct;81(10):9058 .

8. Isgaard J, Aberg D, Nilsson M. Protective and regenerative effects of the GH/IGF-I axis on the brain // Minerva Endocrinol, 2007 Jun;32(2):10313.

\section{Adress:}

Ilze Kreicberga

Department of Obstetrics and Gynecology,

Riga Stradins University

Dzirciema street 16, LV - 1007

E-mail: ilze.kreicberga@rdn.lv 


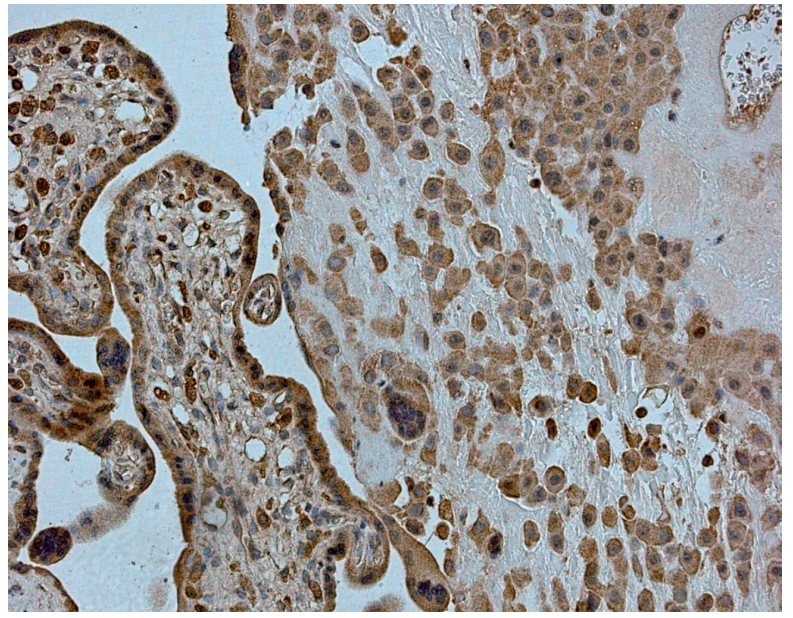

Fig. 1. Placenta A. IGF1 IHC, X 250

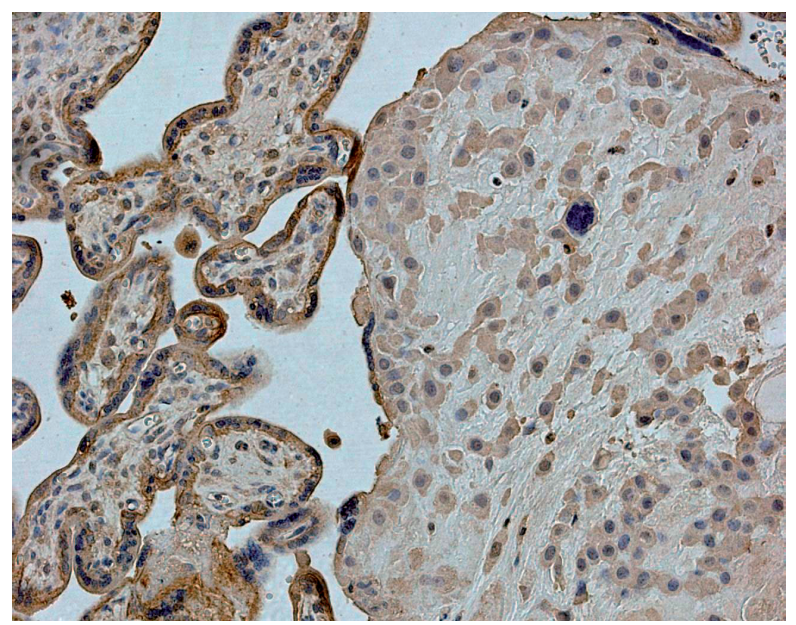

Fig. 3. Placenta A. IGFR I IHC, X 250

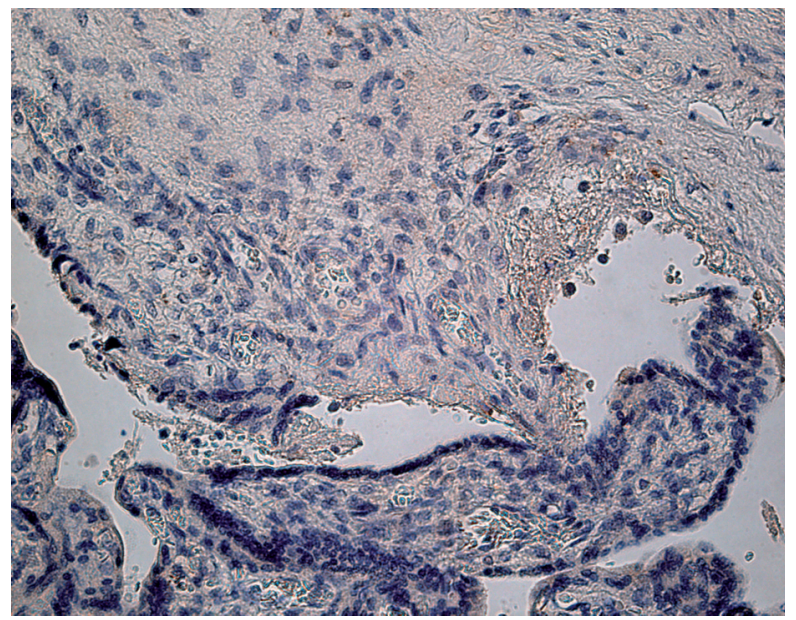

Fig.2. Placenta B. IGF1 IHC, X 250

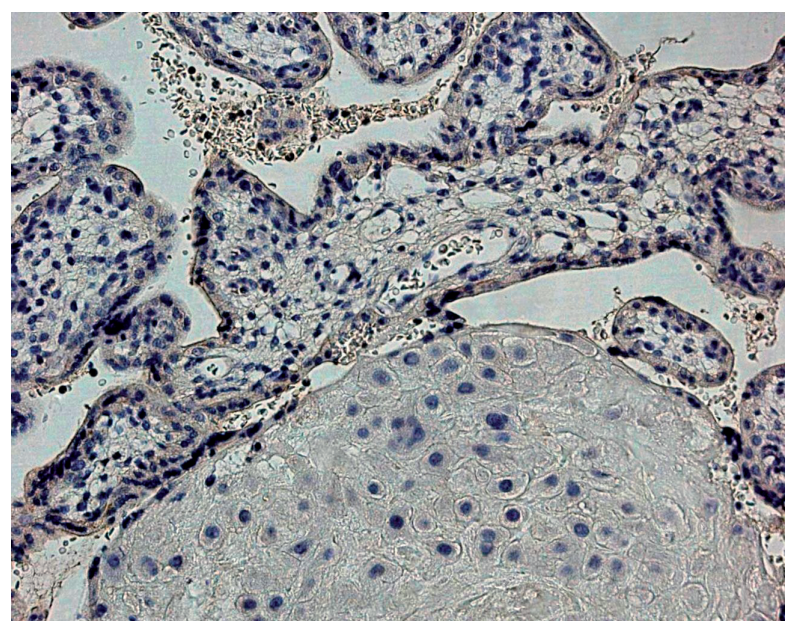

Fig. 4. Placenta B. IGFR I IHC, X 250 